\title{
PENGALAMAN PERAWAT INSTALASI GAWAT DARURAT MERAWAT PASIEN DO NOT RESUSCITATE
}

\author{
Christine Stephanny Lintang ${ }^{a}$, James Richard Maramis ${ }^{a}$ \\ ${ }^{a}$ Faculty of Nursing of Universitas Klabat \\ email: jmaramis@unklab.ac.id
}

\begin{abstract}
ABSTRAK
Latar belakang: DNR atau Do Not Resuscitate merupakan keputusan untuk tidak melanjutkan tindakan CPR, keputasan diambil setelah 30 menit tidak menunjukan ada Return of spontaneous circulation (ROSC) dari pasien. Tujuan: Mengetahui pengalaman perawat IGD merawat pasien do not resuscitate pada fase perawatan end of life di Ruangan IGD RSUP Prof. Dr. R. D. Kandou Manado. Metode Penelitian penelitian kualitatif dengan pendekatan fenomenologi. Pengambilan sampel menggunakan teknik purposive sampling berdasarkan kriteria inklusi. Teknik pengumpulan data dengan In-depth interview. Pastisipan dalam penelitian ini sebanyak empat orang perawat. Hasil: empat tema yang didapati yaitu: Penentuan DNR, Protap Penanganan Pasien, Pengambil Keputusan DNR, dan Proses Setelah DNR Kesimpulan: Pengambilan keputusan DNR (Do Not Resuscitate) yang tepat memerlukan kolaborasi antara dokter dan perawat agar penanganan tepat sasaran sesuai tujuan berfokus pada prioritas tidak dapat membuat keputusan secara sepihak, keterlibatan keluarga dalam penentuan DNR juga penting.
\end{abstract}

Kata kunci : Pengalaman, Merawat, Do Not Resucitate, Gawat Darurat

\begin{abstract}
Background: DNR or Do Not Resuscitate is a decision not to continue the CPR action; the decision taken after 30 minutes does not indicate the Return of Spontaneous Circulation (ROSC) of the patient. Objective: To find out Emergency Department nurses caring expriences for Do Not Resuscitate patients in the end of life treatment phase at the RSUP Prof. Dr. R. D. Kandou Manado. Method: Qualitative research methods with phenomenological approaches was implemented in this research. Purposive sampling technique was used based on inclusion criteria. Data collection techniques with In-depth interviews. The participants of this study were four nurses. Result: Four themes emerged, namely determination of DNR Status, Patient handling procedures, DNR status decision maker, and process following DNR status announced. Conclusion: The proper decision of Do Not Resuscitate requires collaboration between doctors and nurses so that the right handling of the patients, objectives of the treatment, and in order to focus on priorities will not based on unilateral decisions. Family involvement in determining DNR is also important.
\end{abstract}

Keywords : Experience, Caring, Do Not Resucitate, Emergency Room 


\section{PENDAHULUAN}

DNR atau Do Not Resuscitate merupakan keputusan untuk tidak melanjutkan tindakan CPR, keputusan diambil setelah 30 menit tidak menunjukan ada Return of spontaneous circulation (ROSC) dari pasien. Pasien-pasien dengan DNR termasuk dalam kategori sebagai pasien menjelang ajal (end of life). Menurut Emergency Nursing Association salah satu kompetensi perawat IGD yaitu memecahkan masalah dengan mengunakan prinsip etik dalam pengambilan keputusan dan merupakan tanggung jawab dalam memberikan perawatan menjelang ajal atau (Maria, 2017).

Penentuan DNR diputuskan oleh dokter dikolaborsikan dengan pertimbangan yang dikemukakan atau diusulkan oleh perawat sesuai dengan hasil pemeriksaan yang dilakukan. Pengalaman dalam pengambilan keputusan DNR terkait siapa yang berhak menentukan diagnosa DNR sesuai dengan ketentuan yang diberlakukan (Tia, Retty \& Ika, 2015).

Hasil survey pada penelitan yang dilakukan Joice \& Konny (2014), BLU RSUP Prof. Dr. R. D. Kandou
Manado menggambarkan jumlah pasien masuk UGD adalah 36.548 pasien dengan perawatan tindakan resusitasi. Hasil observasi yang dilakukan peneliti didapati kolaborasi antara perawat dan dokter dalam penentuan DNR kurang.

Hasil wawancara peneliti pada salah satu perawat IGD dalam studi pendahuluan menjelaskan makin meningkatnya pasien yang masuk IGD dengan kebutuhan resusitasi. Kurangnya tenaga membuat tidak optimalnya penanganan resusitasi sehingga berpengaruh dalam penentuan DNR untuk pasien. Kegagalan rususitasi lebih besar dibandingkan keberhasilannya dikarenakan kondisi pasien yang datang sudah komplikasi berat dengan kondisi kritis.

Berdasarkan pengalaman peneliti berpraktek di ruang IGD selama 9 hari didapati banyak pasien yang masuk dengan kondisi tidak memungkinkan untuk dilakukan resusitasi sehingga tim medis memutuskan untuk dilakukan tindakan DNR, ada juga keluarga yang menolak setelah dijelaskan sehubungan kondisi yang dialami pasien. Peneliti juga mendapatkan keterlambatan penangan 
dikarenakan banyaknya pasien sedangkan tim medis yang ada masih termasuk kurang.

Berdasarkan uraian diatas peneliti tertarik untuk mengetahui pengalaman merawat pasien do not resuscitate di Ruangan IGD RSUP Prof. Dr. R. D. Kandou Manado.

\section{METODE PENELITIAN}

Penelitan ini merupakan penelitian kualitatif dengan pendekatan fenomenologi interpretif. Pengambilan sampel menggunakan teknik purposive sampling berdasarkan kriteria inklusi. Pastisipan dalam penelitin ini ada empat orang perawat.

Teknik pengumpulan data dengan In-depth interview. Adapun kriteria partisipan adalah: (1) Perawat yang memiliki pengalaman kerja $>5$ tahun di ruang IGD RSUP PROF. DR. R. D. KANDOU MANADO, (2) Perawat yang memiliki pengalaman pengalaman merawat pasien DNR (3) Dalam keadaan sehat secara fisik, (4) Bersedia sebagai partisipan dengan menandatangani surat ke-sediaan menjadi partisipan. Pada penelitian ini, saturasi data dicapai pada wawancara partisipan ke empat. Analisis data pada penelitian ini dilakukan dengan menggunakan analisis tematik Braun dan Clarke dalam Rohmah (2015) yang terdiri dari 6 tahapan yaitu mengenali data dengan mewawancarai praktisi, memberi kode dari hasil wawancara, mencari tema, meninjau tema, mendefinisikan tema, menghasilkan laporan.

Penelitian ini dilakukan di ruangan IGD RSUP Prof. Dr. R. D. Kandou Manado pada tanggal 16 Maret 2018. Berdasarkan 6 tahapan yang telah dijabarkan maka peneliti menyusun hasil penelitian yang dapat dilihat dalam penjabaran hasil dan pembahasan berikut ini.

\section{HASIL}

Hasil penelitian ini ada 4 (empat) tema yaitu: Penentuan DNR, Protap Penanganan Pasien, Pengambil Keputusan DNR, dan Proses Setelah DNR

\section{Penentuan DNR}

"...ciri-cirinya rupa depe respirasi brapakali permenit rupa so ngap-ngap begitu dang abis pernafasan depe nadi, kondis wajah pasien, nadi karotis nda taraba, depe pupil, saturasi...” P1

“...biasanya pasien-pasien DNR itu yang kalo molia dari depe tanda-tanda dang dia so kemungkinan kalo mo bantu 
alat itu Cuma menyiksa dengan

ada juga karna depa jantung itu so berhenti, nadi sudah tidak teraba, tensi sudah tidak terukur. Pas semtara RJP juga torangkan semaso suntikan kong EKG kan terpasang kong torang lia so nda ad peningkatan sudah noh torang iko langsng sebrenti...” P2

“...kalo mo bilang pasien kategori resusitasi itu yang mo dibilang ancaman gagal napas toh, dia perdarahan, ato dia shock ato biasa dia kardiak arrest, yaa kalo so kardiak arrest dia resus, dari muka kan dorang so lia dia ada tanda sianosis, ada ancaman gagal napas, pas pasang EKG so nda dapa baca, biar mo pasang alat nda mo ta bantu, kira-kira begitu noh... ’’P4

Pernyataan diatas sesuai dengan apa yang dijelaskan Maria dalam penelitiannya. Kegagalan resusitasi harus dipahami dengan mengetahui secara pasti kondisi pasien dengan DNR (Do Not Resuscitate). DNR adalah perintah untuk tidak melakukan tindakan resusitasi. Pada umumnya pasien dengan DNR sudah dilakukan tindakan resusitasi namun tidak menunjukan adanya perubahan keadaan ke kondisi yang lebih baik dilihat dari kondisi TTV, SpO2 maupun tingkat kesadaran (Maria, 2017).

Penentuan DNR didasarkan pada kondisi pasien mencakup umur, jenis kelamin, riwayat comorbid dan harapan hidup (Tia \& Cornelia. 2017) sejalan dengan itu Perron, Marobia, Torrente (2018) dalam penelitianya mengemukakan penentuan DNR ditentukan bedasarkan status pasien dari dokumen yang perawat susun mulai dari umur, jenis kelamin, status kesehatan pasien (medical diagnosis) dan tingkat perkembangan mental klien (Maria, 2017).

DNR juga dapat ditentukan dalam kondisi pasien dangan penyakit terminal dalam status kritis yang sudah tidak menunjukan adanya perbaikan (Maria, 2017) ini sejalan dengan penelitian yang dilakukan Saczynski, Gabbay \& Goldberg (2012) mengemukakan faktor-faktor atau karakteristik penyakit yang mengambil bagian dalam menentukan DNR pada pasien seperti angina pectoris, DM, hipertensi, heart failure, storke, AMI, cardiogenic shock. Hal ini seperti yang diungkapkan perawat :

“...biasanya lee pasien DNR so deng penyakit komplikasi, faktor umur, deng resko-resiko 
tinggi leh toh, biasanya deng so sepsis.. ” $\mathrm{P} 3$

“...kalo dari torang tim medis juga balia kalo itu pasien ada fraktur rusuk, hematemesis, ada tumor dilaring itu biasanya trang so nda lakukan resusitasi, kadang le dorang datang rujukan so saki parah dulu baru sampe.. ’P2

“...deng le kalo pasien ada syok, deng kalo datang penyakit jantung yang so parah so nda mo dilakukan RJP it.." $\mathrm{P} 4$

\section{Protap Penanganan Pasien}

Pada saat pasien datang ke IGD pasien dengan kemungkinan ada penyakit terminal yang memiliki penurunan kesadaran perawat harus akan melakukan pengkajian atau anamnesa. Setelah dikaji pasien akan dilakukan penilaian triage yang akan menentukan tindakan resusitasi berdasarkan prioritas. Pemeriksaan penungjang dalam pengkajian atau anamnesa sangat penting untuk dilakukan untuk menentukan tindakan resusitasi dan atau DNR (maria. 2017)

“...biasanya dari primer itu langsung ke triage dari triage kalo perkiraan pasien memang harus diresusitasi langsung ke ruang resusitasi Cuma depe penentuan pas di triage, pas so didalam resusitasi langsung dianamnesa lengkap...” $\mathrm{P} 2$ “...pas datang tetap maso triage nah disitu dorang yang ba pila-pila apakah dia momaso merah ruang resusitasi ato cma momaso imed, sebelum itu juga pasti harus di anamnesa dulu..” P3

\section{Pengambil Keputusan DNR}

DNR dilaksanakan atas permintaan pasien dan keluarga serta atas pertimbangan dari tim medis (Tia \& Cornelia. 2017).

Penentuan DNR diputuskan oleh dokter dikolaborasikan dengan pertimbangan yang dikemukan atau diusulkan oleh perawat (Tia., Retty \& Ika. 2015). DNR tidak dapat di tentukan sepihak perlu ada pertimbangan agar penanganan berpusat pada pasien sesuai dengan tujuan dan prioritasnya (Dunlay, Swetz., \& Redfield, 2014).

“...kalo untuk menentukan DNR dikolaborasi dengan dokter dengan petugas medis lain, sebelum perawat menentukan dokter tu sudah menjelaskan lebih dulu... ’P2 
Selain perawat dan dokter keluarga juga mengambil bagian dalam penentuan DNR. Pham, et al (2011) menjelaskan bahwa keluarga memilik hak dalam pengambilan keputusan termasuk penentuan dilakukan atau tidak dilakukan DNR terhadap pasien, keterlibatan keluarga merupakan bagian dari SOP.

“...biasanya juga untuk tidak melalukan resusitasi berdasarkan putusan keluarga ,keluarga yang menentukan sendiri dia itu nda mo lakukan tindakan resusitasi.. " P2

“...kalo keluarga so lia memang so nda ada harapan keluarga langsung bilang "biarjo sus" biasanya sebelum dorang ambil tindakan begitu sudah diedukasi dulu dari dokter depe tingkat keberhasilan pengobatan trus RJP lagi depe tingkat keberhasilan berapa persen ada katu yang lanjut ada katu yang langsung stop..” P3

\section{Proses Setelah DNR}

Perawatan

pasien

membutuhkan penanganan yang bertujuan untuk memberikan rasa nyaman, ketenangan, kedekatan suport sosial. Dalam hasil penelitianya, Maria Retty \& Retno dapat disimpulkan bahwa untuk menunjang keberhasilan perawatan perlu dilakukan pendampingan serta support untuk keluarga. Pernyataan diatas sesuai dengan pernyataan perawat yang telah diwawancarai berikut ini.

“...libatkan keluarga jelaskan depe penyakit apa proses tindakan deng tetap damping kong kase penguatan begitu.." P3

“...setelah dokter putuskan sudah meninggal sebelumnya penjelasan ke keluarga itu dari dokter setelah itu perawat jelaskan abis itu menguatkan keluarga...”P2

\section{PEMBAHASAN}

DNR atau do not resuscitation adalah tindakan yang dilakukan kepada pasien untuk mendapatkan kenyamanan tidak dilakukan CPR atau cardio pulmonary resuscitation serta menghentikan alat bantu hidup berdasarkan keputusan dan pertimbangan baik dari keluarga dan atau tim medis yang ada (Tia \& Cornelia, 2017). 
Penentuan DNR diambil ketika tindakan CPR selama 30 menit tidak menunjukan adanya respon pasien untuk pernafasan, nadi serta penurunan respon kesadaran. Suatu tindakan memberikan resusitasi jantung paru namun tetap melakukan perawatan rutin dapat disebut dengan tindakan DNR (Brizzi, 2012).

Penentuan DNR dapat didasarkan pada kondisi pasien seperti umur, jenis kelamin, harapan hidup (Tia \& Cornelia, 2017) sejalan dengan itu Junod, Marobia, A de Torrente (2018) dalam penelitianya mengemukakan penentuan DNR ditentukan mulai dari umur, jenis kelamin, status kesehatan pasien (medical diagnosis) dan tingkat perkembangan mental klien berdasarkan status pasien dari dokumen yang perawat susun. (maria, 2017). Ada pun menurut Brizzi (2012) kriteria pasian DNR yaitu pasien yang berusia >75 tahun dan mengalami kondisi seperti penurunan fungsi organ, mengalam stroke serta perdarahan pada intraventicular terkait tidak berhasilnya proses CPR yang telah dilakukan.

Penentuan DNR harus didasarkan atas kesepakatan antara dokter dan perawat didasari dengan hasil anamnesa yang telah dilakukan atas persetujuan dari keluarga pasien.

Kolaboras dan kerjasama dapat mengarahkan agar tim medis dapat bertanggung jawab dalam setiap penanganan perawatan pasien. Semakin baik kolaborasi dan kerjasama maka tindakan perawatan akan masimal (Maria, 2017).

Dalam perawatan pasien diperlukan sikap menghargai harkat dan martabat pasien. Perawat harus menunjukan nilai-nilai humanistic (rasa kemanusian) dengan nilai kebaikan, empati dan caring pada pasien dengan mengutamakan kepentingan pasien yang akan berdampak rasa kebahagian dan kepuasaan dari perawat tersebut. Penelitian ini sejalan dengan penelitian yang dilakukan Eva, Sri \& Retno (2015) dimana perawat harus menghargai harkat dan martabat keluarga dalam proses perwatan.

Pemberian perawatan bermartabat juga tetap harus dilakukan. Pemberian perawatan bermartabat merupakan bentuk dari pemberian care pada pasien DNR. Perawatan yang bermartabat pada pasien meliputi perawatan tanpa adanya diskriminasi terhadap suku atau kelompok tertentu. Standart perawatan yang sama akan membantu pelaksanaan perawatan bermartabat (Tia \& Cornelia, 2017). 


\section{KESIMPULAN}

Penentuan untuk melakukan DNR di ruangan IGD RSUP Prof. Dr. R. D Kandou Manado sudah sesuai dengan ketentuan yang ada. Pengambilan keputusan DNR (Do Not Resuscitate) yang tepat memerlukan kolaborasi antara dokter dan perawat agar penanganan tepat sasaran sesuai tujuan berfokus pada prioritas tidak dapat membuat keputusan secara sepihak, keterlibatan keluarga dalam penentuan DNR juga penting. Alur penanganan pasien yang dilakukan oleh tim medis sudah sesuai dengan standar yang ditetapkan rumah sakit.

\section{SARAN}

Bagi Rumah Sakit

Dapat mepertahankan standar dan mutu pelayanan dalam protap penanganan pasien DNR di ruang gawat darurat.

\section{Bagi Perawat Ruangan \\ Perawat tetap berperan penting dalam kolaborasi tim medis untuk penentuan DNR serta penanganan lanjutan setelah DNR ditentukan. Bagi Keluarga}

Untuk mengambil keputusan DNR keluarga perlu mempertimbangkan dengan baik serta memahami pentingnya pendapat tim medis.

Bagi Peneliti Selanjutnya

Diharapkan dapat melakukan penelitian selanjutnya dengan meneliti bagaimana perasaan baik perawat atau dokter dalam menjelaskan keputusan DNR yang telah dambil kepada keluarga.

\section{Daftar Pustaka}

Brizzi, M., Abul, K, K., Jalakas, M., Selariu, E., Pessah-Rasmussen, H., \& Zia, E. (2012). Early donot-resuscitate orders in intracerebral haemorrhage; frequency and predictive value for death and functional outcome. A retrospective cohort study. Scandinavian journal of trauma, resuscitation and emergency medicine, vol 20 no 1, ha 1-6.. diakses dari: http://www.ncbi.nlm.nih.gov/ar ticle

Dunlai, S, M., Swets M, K \& Redfield M, M. (2014). Resuscitation preference in community parients with hearth failure. circ cardiovasc qual outcomes. vol 7 no 3 ha 353-359 Diakses dari : www.ncbi.nml.nih.gov 
Eva, M., Sri, A \& Retno, L. (2015).

Studi fenomenologi penerapan prinsip patient Centered care pada saat proses resusitasi Di igd rsud saiful anwar malang. the indonesian journal of health science, vol. 6, no. 1. Ha 73-89. Diakses dari : http://jurnal.unmuhjembeer.ac.i d/index.php/article

Joice, M, L \& Konny, R. (2014) Gambaran pengetahuan perawat Pelaksana dalam penanganan pasien gawat darurat di ruangan igdm blu rsup. Prof. Dr. R. D kandou manado. juiperdo, vol 3, no. 2.

Diakses dari:

http://download.portalgaruda.or g/article

Maria I, O (2017). Pengalaman Perawat Igd Merawat Pasien Do Not Resuscitate Pada Fase Perawatan Menjelang Ajal. Jurnal Keperawatan Indonesia, Vol 20 No.1, ha 1-8. Diakses dari :

http://www.neliti.cm/publicatio $\mathrm{n} / 107335$

Maria, I, O., Retty, R \& Retno L (2016). Studi fenomenologi pengalaman perawat instalasi gawat darurat (igd) dalam merawat pasien terlantar pada fase end of life di rsud dr. Saiful anwar malang. Jurnal Ilmu Keperawatan, Vol:4, No.2 . hal 171-183 diakses dari : www.jik.ub.ac.id
Perron., N., J., Morabia., A \& Torrenté A., D (2018). Evaluation of do not resuscitate orders (DNR) in a Swiss community hospital. Diakses dari http://jme.bmj.com/

Pham, J.C., Trueger, S., hilton, J., Khare, R. K., Smith, J. P., \& Bernstein, S. L. (2011). Interventions to Improve Patient-centered Care During Times of Emergency Department Crowding. Academic Emergency Medicine. Vol 18 no 12. Diakses dari: https://www.ncbi.nlm.nh.gov/ar ticle

Rohmah, D., F. (2015). Keharmonisan rumah tangga pada keluarga yang tidak memiliki anak (involuntary childless) studi kasus disusun krajan keluarahan sukorjo kecamatan malo kabupaten bojonegoro. Kesehatan psikologi. Diases dari : http//digilib.uinsby.ac.id/id/epri nt/4022

Saczynski, J, S., Ezra, G \& Robert J, G. (2012). Increase in the proportion of patients hospitalized with acute myocardial infaction with donot-resuscitate orders already in place between 2001-2007:a nonconcurrent prospective study.clin epdemiol. 4. 267274. Diakses dari : www.ncbi.nml.nih.gov 
Tia, A,. Cornelia D, Y \& Nekada.

(2017). Hubungan Pengetahuan

Perawat Tentang Do Not

Resuscitation (Dnr) Dengan

Sikap Merawat Pasien Di Icu

Rsud Panembahan Senopati

Bantul. Jurnal Keperawatan

Respati Yogyakarta, vol 4 no

2,ha 138-141. Diakses dari :

http://nursingjurnal.respati.ac.id

/index.php/JKRY/index

Tia, A., Retty, R \& Ika S, R. (2015)

Studi Fenomenologi:

Pengalaman Perawat Dalam

Merawat Pasien Dengan Do

Not Resuscitate (Dnr) Di

Ruang Icu Rsup Dr. Soeradji

Tirtonegoro Klaten. Jurnal

Medika Respat. ISSN : 1907 388. Diakses

dari:http://nursingjurnal.respati. ac.id/index.php/article/downloa d 